\title{
WHO ARE THE BIG TIPPERS? SEGMENTING TIPPERS BASED ON THE SIZE OF THE TIP
}

\author{
Melville Saayman* \\ North-West University
}

Received: September 2015

Accepted: January 2016

\begin{abstract}
The purpose of this research is to distinguish big tippers from other categories or types of tippers. In this context four types have been identified: those who do not tip, those who tip sometimes, those who tip regularly and those who always tip. A survey was conducted, during a National Arts Festival held in Potchefstroom, South Africa, where 400 questionnaires were distributed, of which 374 were used in the statistical analysis. Results confirmed that different types of tippers exist and that those who tip always are more affluent; the quality of the food as well as the quality of the service were identified as further determinants of tipping. This research determines the reasons why people dine out and how those reasons influence tipping. In addition, reasons why people tip or do not tip were identified. This is one of just four studies conducted on this topic in Africa and the first of its kind in South Africa.
\end{abstract}

Keywords

Tipping behaviour, tipping categories, tipping at festivals, restaurants, determinants

*Prof M Saayman is professor and director of the Tourism Research in Economic Environs and Society, North-West University, South Africa [Melville.Saayman@nwu.ac.za] 


\section{INTRODUCTION}

Significant numbers of workers in various occupations in the tourism and hospitality industry are partially or fully dependent on the tips that they receive. Some of the occupations that derive benefits from tipping include street artists, bus and taxi drivers, washroom attendants, porters, casino croupiers, barmen, doormen, car guards, tour guides, field guides, delivery staff, golf caddies, exotic dancers and waiters and waitresses (Saayman, 2014). According to Miller (2010) 3 million of the 4.7 million food service sector employees in the USA earn an income from tipping. Statistics concerning the economies of tipping in other parts of the world are scant, which therefore makes it difficult to determine a comprehensive view of how many people benefit from tipping, but based on the meagre information that is available, it is clear that tipping touches the lives of millions of people in the industry.

Tipping behaviour differs from one country or culture to the next (Mkono, 2011) and, according to Barkan, Erev, Zinger and Tzach (2004), the practice of tipping can facilitate a high quality of service. For example, in terms of tipping behaviour, in the USA patrons tip between $15-20 \%$ while in South Africa, as in many other countries, it is $10 \%$ (Saayman 2014). In terms of tipping and service quality, it seems that customers who tip might be in a better position to enhance the performance of staff (Lynn \& McCall 2000). Therefore, tipping allows customers to reward satisfactory service delivery (Bodvarsson \& Gibson 1994). This implies that patrons differ in their tipping behaviour and based on this, one could then argue that there are different markets or types of tippers and that these categories of tippers will have different socio-demographic profiles and behaviour. Azar (2011) found that the majority of research done on the topic of tipping is in the area of motivation: in other words, why patrons tip. An area which has not been well researched is the identity of these patrons who tip and how one may distinguish big tippers from those who tip less. In addition, how do these "markets" of tippers differ? Answers to these questions will help academics and practitioners gain a better understanding of tipping behaviour and will also be useful in setting guidelines for restauranteurs. Therefore, this article will attempt to address the issues raised above.

\section{LITERATURE REVIEW}

Tipping, which is the voluntary act of leaving money as appreciation for a service received, is fraught with ambiguities and complexities (Thomas-Haysbert, 2002). Lynn and Withiam (2008) state that tipping is a form of voluntary payment usually occurring after a face to face service has been provided. According to him, it is a practice that was started in the $18^{\text {th }}$ century by guests who left money to ensure good or prompt service, although the Bible (2011, see Luke $10: 35)$ refers to the Good Samaritan who also left an amount (2 Denarii) to ensure good service, which shows that this practise is much older. Today, restaurateurs have different approaches or systems in place to facilitate the process of tipping. For example, there is individual tipping; pooling of tips that are then equally divided; a service charge with a percentage going to the waiter/waitress; a system where tips are included in the bill or, in the case of larger groups, a fixed percentage is then added to the bill (Namasivagim \& Upenja, 2007). Regardless of the systems used, some patrons are more prone to tip than others and some leave much bigger tips than others. In this regard Bujisic et al. (2013) found that the typical tipper would leave a tip up to $20 \%$ of the size of the bill, although this differs from country to country, as previously mentioned. 
Research concerning the reasons why patrons tip could also influence this study, since the said reasons are part of tipping behaviour. Previous research confirms that patrons tip since it ensures good quality service (Lynn \& McCall 2000), guarantees future service (Azar 2005), conforms to social norms and for social approval (Azar 2007) as well as out of empathy for the workers (Lynn \& Grassman 1990; Speer 1997; Saayman 2014; Whaley, Douglas \& O'Neil 2014; Saayman \& Saayman 2015). These and other reasons are described as being influenced by socio-demographic and behavioural determinants, such as race, education, income (Thomas-Haysbert 2002), when people are on holiday (Greenberg 2014), the behaviour and gestures of the server (Seiter \& Weger, 2013), size of the bill (Lynn \& McCall 2000), method of payment (Lynn, 2006; Saayman \& Saayman, 2015), size of the dinner party (Lynn, 2006), frequency of visiting the restaurant (Lynn \& McCall 2000), the weather (Rhind \& Strohmeta 2001) and where the restaurant is located (Lynn \& Thomas-Haysbert 2003).

Research by Thomas-Haysbert (2002) found that only $2 \%$ of respondents did not tip, which is lower percentage in terms of research completed 55 years ago by Crespi (1947) who found that $3.8 \%$ of respondents at restaurants did not tip. However, several studies alluded to the different types of tippers that are predominantly influenced by the size of the bill (Lynn 2006) such as those that leave a small tip if the size of the bill is small and vice versa. However, a recent study conducted by Saayman and Saayman (2015) revealed that the patrons who are willing to pay more than the customary $10 \%$ in the case of South Africans, are influenced more by the quality of the service. Over and above, these tippers are also those who give the same amount (flat rate) regardless of the size and then those that who add a specific percentage, for example 10\% (Lynn \& Sturman 2003). Lastly, there are those who round up amounts; for example, if the bill is $\$ 18.00$ they will give $\$ 20.00$ (Azar, 2004). Surveys undertaken in the USA found that $20 \%$ of tippers leave a flat dollar amount rather than a percentage (Paul \& Gardyn, 2001). The limited information available not only necessitates the need for more research on this aspect, but also expands the research further to include tipping profiles, different markets or categories of tippers in order to distinguish between big and small tippers.

\section{METHODOLOGY}

\subsection{The survey}

This research was carried out by means of a structured questionnaire and the survey was conducted at one of the largest national arts festivals in South Africa, the Aardklop National Arts Festival during September 2013 in the city of Potchefstroom. The reason for choosing this event was that a large number of visitors also dine out during their stay at the festival. In addition, the festival offers the visitor many dining opportunities, which made it more affordable to conduct research amongst consumers or visitors in order to gain insight into their view on tipping as well as dining behaviour. Previous research by Saayman and Saayman (2006) and van Wyk et al. (2013) indicated that visitors spend a significant amount on restaurants and dining out during arts festivals in South Africa.

The abovementioned questionnaire was primarily based on research conducted by Lynn (2006) and Azar (2011) and consisted of three sections. Section A focussed on socio-demographic information, such as gender, age, income, where visitors come from (place of origin) and occupation. Section B focussed on the aspects that influence tipping, such as the waiters, the restaurant, dining party etc. Section $C$ assessed the reason why patrons do or do not tip. The survey 
was conducted from 25-28 September 2013, where the fieldworkers randomly distributed 400 questionnaires at the various restaurants. From the 400 distributed, 374 were used in the analysis.

\subsection{Data analysis}

The data were captured in Microsoft $\varepsilon x c e{ }^{\circledR}$ and the variables were coded in the same programme. Two distinct analyses were used in the article: a principal component analysis and ANOVA. In order to reduce the number of statements concerning four sets of questions: the reasons for dining out, which factors influence the size of the tip, reasons for tipping and reasons for not tipping; each set of statements was subjected to principal component analysis using the Statistical Package for Social Sciences (SPSS) version 22.

The Kaiser-Meyer-Olkin (KMO) measure of sample adequacy and Bartlett's Test of Sphericity were used to determine whether the data were suitable to be reduced using principal component analysis (Field, 2009:658-659). In all cases the KMO was above 0.84 and Bartlett's test is significant at a $1 \%$ level of significance, indicating that all four groups of statements could be subjected to principal component analysis.

The number of factors extracted for each set of statements was based on Kaiser's criterion, i.e. factors with eigenvalues greater than unity. To improve interpretation of the various factors, oblique rotation was used in the analyses. Factor scores are calculated using the Anderson-Rubin method, which leads to uncorrelated and standard normally distributed factor scores (Field, 2009:640-644, 635). The results of the analysis identified three reasons why people dine out, with eigenvalues greater than unity that explain $60 \%$ in the variance. Four factors with eigenvalues greater than one were identified to explain $55 \%$ of the variance in the tipping decision. Three factors explain more than $65 \%$ of the variance in the reasons why patrons tip. Finally, two factors explain more than $65 \%$ of the variance in the reasons why patrons do not tip.

Analysis of variance or ANOVA was also conducted, which is a statistical procedure that utilises the $F$-ratio to test the overall fit of a linear model. In experimental research, as in the case of this article, the linear model tends to be defined in terms of the group means and the resulting ANOVA is therefore an overall test of whether group means differ after the variance in the outcome variable is explained by any covariates that have been removed (Field, 2009). After the ANOVA was applied it was also necessary to apply the Bonferroni correction. The said correction is applied to the $\alpha$-leve/to control the overall Type 1 error rate when multiple significance tests are carried out. Each test conducted should use a criterion of significance of the $\alpha$-level (normally .05) dived by the number of tests conducted (Field, 2009). In other words, the Bonferroni correction provides an indication of where the significance amongst the type of tippers occurs.

\section{RESULTS}

\subsection{Results of the factor analysis}

Results from the four factor analyses conducted above were as follows: Three factors or reasons for dining out were identified: Status that captured constructs such as "status associated with dining at fine restaurants" and "I consider myself to be a foodie" etcetera scored a mean value of 2.76, while Gastronomy consisting of "enjoying food at a specific restaurant", "I enjoy great food" and "for convenience" etc. scored a mean value of 3.45, and lastly Socialization with 
constructs such as "celebrating special occasions", "to socialize" and "to meet family and friends" scored the highest mean value of 3.63 .

Answers to the question vis-à-vis which aspects or factors influence tipping or the amount patrons willing to tip, formed part of the second factor analysis. Four factors were identified and labelled in this regard: Restaurant attributes (type of restaurant influences my tipping, location, good weather and the type of waiter), Hospitality and service (the waiter's knowledge regarding the menu, I tip friendly waiters more, well trained quality servers), Payment and bill (the greater the size of the bill the higher the percentage tip and method of payment) and Standardisation (service fees should be standardised, a type of flat rate). The factor that has the largest influence on respondents' tipping behaviour was found to be hospitality and level of service at the restaurant with a mean value of 3.58 , followed by method of payment and size of the bill with a mean value of 3.20 and standardisation, which had a mean value of 3.17. Restaurant attributes had the lowest mean value of all the factors, scoring just 2.59 .

Results of the factor analysis dealing with reasons for tipping identified three factors: Financial (it contributes to the waiters' income, I support the rule of tipping, I feel positive when I tip, etc.) with a mean value of 3.59 which was the highest of the three factors. Secondly, service, which included constructs such as "waiters are friendlier with return visits", "it ensures that future service delivery is good" and "tipping is a social norm and is expected of me". Service had a mean value of 3.54 , which closely resembles the highest mean value. The third factor was labelled social acceptability which entails that tipping "...contributes to my social status" and "I receive social approval from my dining party" and scored the lowest mean value of 2.7 .

Results of the fourth and last factor analysis concerning the reasons why patrons do not tip revealed two distinct factors: bad service (bad personal service, when waiters are rude and no response when I order etcetera) scored the highest with a mean value of 3.56 , while the second factor, labelled inessential, scored a mean value of 2.51 and consisted of constructs such as: "I don't think it is necessary", "they earn a salary" and "they should be paid a minimum wage".

\subsection{Results of the ANOVA}

The dependent variable was frequency of tipping; in this regard four categories were used: do not tip, tip sometimes, tip regularly and tip always. Most of the respondents were categorised as tippers who do so always or regularly. Results recorded in TABLE 1 reveal three socio-demographic variables that are significant: language, occupation and income. Interestingly, more English than Afrikaans speaking patrons tip always and in terms of occupation, all categories tip always with the exception of students, who also had the highest number of respondents in the category of $d o$ not tip. The latter is understandable since they do not earn a fixed salary. Income also revealed interesting results where the R300000 - R400000 income bracket has the highest number of always-tippers; however, the majority of the income bracket categories tip regularly or always.

Based on the results of the ANOVA, it is clear that age is the only socio-demographic variable that is significant and may therefore be seen as a determinant of tipping. In terms of the reasons for dining out, gastronomy was found to be significant and confirms the importance of the food experience as well as of quality food. Concerning the factors that influence the size of the tip, method of payment and size of the bill as well as hospitality and servicewere significant variables. One significant reason for tipping was found to be financial. When it comes to reasons for not tipping, inessentia/ was the sole significant variable. Total spending was also significant and confirms that the size of the bill influences tipping (see TABLE 2). 
Saayman

TABLE 1: Descriptive statistics

\begin{tabular}{|c|c|c|c|c|c|}
\hline Descriptive Statistics & Do Not Tip & $\begin{array}{c}\text { Tip } \\
\text { Sometimes }\end{array}$ & $\begin{array}{c}\text { Tip } \\
\text { Regularly }\end{array}$ & Tip Always & $\begin{array}{l}\text { Sig. } \\
\text { Level }\end{array}$ \\
\hline LANGUAGE & & & & & 0.021 \\
\hline Afrikaans & $6.1 \%$ & $19.0 \%$ & $36.9 \%$ & $38.0 \%$ & \\
\hline English & $0.0 \%$ & $10.5 \%$ & $21.1 \%$ & $68.4 \%$ & \\
\hline Other & $50.0 \%$ & $0.0 \%$ & $0.0 \%$ & $50.0 \%$ & \\
\hline OCCUPATION & & & & & 0.010 \\
\hline Professional & $2.8 \%$ & $11.1 \%$ & $41.7 \%$ & $44.4 \%$ & \\
\hline Management & $3.6 \%$ & $7.1 \%$ & $35.7 \%$ & $53.6 \%$ & \\
\hline Self-employed & $2.6 \%$ & $15.8 \%$ & $23.7 \%$ & $57.9 \%$ & \\
\hline Administrative & $3.3 \%$ & $16.7 \%$ & $13.3 \%$ & $66.7 \%$ & \\
\hline Student & $10.7 \%$ & $26.2 \%$ & $33.3 \%$ & $29.8 \%$ & \\
\hline INCOME & & & & & 0.014 \\
\hline$<\mathrm{R} 20,000$ & $10.0 \%$ & $31.3 \%$ & $28.8 \%$ & $30.0 \%$ & \\
\hline $\mathrm{R} 20,001-\mathrm{R} 140,000$ & $2.6 \%$ & $18.4 \%$ & $44.7 \%$ & $34.2 \%$ & \\
\hline $\mathrm{R} 140,001-\mathrm{R} 221,000$ & $4.1 \%$ & $16.3 \%$ & $36.7 \%$ & $42.9 \%$ & \\
\hline$R 221,001-R 305,000$ & $2.3 \%$ & $9.3 \%$ & $44.2 \%$ & $44.2 \%$ & \\
\hline R305,001 - R431,000 & $4.3 \%$ & $4.3 \%$ & $30.4 \%$ & $60.9 \%$ & \\
\hline $\mathrm{R} 431,001-\mathrm{R} 552,000$ & $6.7 \%$ & $20.0 \%$ & $26.7 \%$ & $46.7 \%$ & \\
\hline$>\mathrm{R} 552,001$ & $2.1 \%$ & $14.6 \%$ & $25.0 \%$ & $58.3 \%$ & \\
\hline
\end{tabular}

Source: Author's calculations 
WHO ARE THE BIG TIPPERS? SEGMENTING TIPPERS BASED ON THE SIZE OF THE TIP

TABLE 2: Results of ANOVA

\begin{tabular}{|c|c|c|c|c|c|}
\hline & Sum of Squares & $d f$ & Mean Squares & $F$ & Sig \\
\hline AGE & 1662.266 & 3 & 554.089 & 2.977 & $0.032 \star$ \\
\hline STATUS & 1.885 & 3 & .628 & .630 & 0.596 \\
\hline GASTRONOMY & 9.759 & 3 & 3.253 & 3.312 & $0.020 *$ \\
\hline SOCIALISATION & 3.393 & 3 & 1.131 & 1.130 & 0.337 \\
\hline RESTAURANT ATTRIBUTES & 3.560 & 3 & 1.187 & 1.194 & 0.312 \\
\hline HOSPITALITY AND SERVICE & 8.796 & 3 & 2.932 & 2.965 & $0.032 \star$ \\
\hline PAYMENT AND BILL & 8.771 & 3 & 2.924 & 2.973 & $0.032 \star$ \\
\hline STANDARDISATION & 1.451 & 3 & .484 & .483 & 0.694 \\
\hline FINANCIAL & 16.799 & 3 & 5.600 & 5.830 & $0.001 *$ \\
\hline SERVICE & 5.496 & 3 & 1.832 & 1.847 & 0.138 \\
\hline SOCIAL ACCEPTABILITY & 1.331 & 3 & .444 & .440 & 0.724 \\
\hline BAD SERVICE & 2.619 & 3 & .873 & .902 & 0.440 \\
\hline INESSENTIAL & 12.636 & 3 & 4.212 & 4.466 & $0.004 *$ \\
\hline TOTAL SPENDING & 234861700.465 & 3 & 78287233.488 & 5.914 & $0.001 *$ \\
\hline
\end{tabular}

Source: Author's calculations

*Significance less than $<0.05$ 
Saayman

TABLE 3: Bonferroni corrections

\begin{tabular}{|c|c|c|c|c|c|c|c|}
\hline & \multicolumn{2}{|c|}{$\begin{array}{c}\text { BONFERRONI- } \\
\text { DEPENDENT VARIABLE }\end{array}$} & $\begin{array}{c}\text { Mean } \\
\text { Difference } \\
(1-J)\end{array}$ & Std. Error & Sig. & \multirow{2}{*}{$\begin{array}{c}\begin{array}{c}\text { Lower } \\
\text { Bound }\end{array} \\
-11.38\end{array}$} & \multirow{2}{*}{$\begin{array}{c}\text { Upper } \\
\text { Bound }\end{array}$} \\
\hline \multirow{12}{*}{ U్⿺𠃊 } & \multirow{3}{*}{ DO NOT TIP } & TIP SOMETIMES & -2.142 & 3.483 & 1.000 & & \\
\hline & & TIP REGULARLY & -2.377 & 3.277 & 1.000 & -11.07 & 6.32 \\
\hline & & TIP ALWAYS & -6.331 & 3.254 & .315 & -14.97 & 2.30 \\
\hline & \multirow{3}{*}{$\begin{array}{c}\text { TIP } \\
\text { SOMETIMES }\end{array}$} & DO NOT TIP & 2.142 & 3.483 & 1.000 & -7.10 & 11.38 \\
\hline & & TIP REGULARLY & -.234 & 2.062 & 1.000 & -5.71 & 5.24 \\
\hline & & TIP ALWAYS & -4.189 & 2.026 & .236 & -9.56 & 1.19 \\
\hline & \multirow{3}{*}{$\begin{array}{c}\text { TIP } \\
\text { REGULARLY }\end{array}$} & DO NOT TIP & 2.377 & 3.277 & 1.000 & -6.32 & 11.07 \\
\hline & & TIP SOMETIMES & .234 & 2.062 & 1.000 & -5.24 & 5.71 \\
\hline & & TIP ALWAYS & -3.954 & 1.648 & .102 & -8.33 & .42 \\
\hline & \multirow{3}{*}{ TIP ALWAYS } & DO NOT TIP & 6.331 & 3.254 & .315 & -2.30 & 14.97 \\
\hline & & TIP SOMETIMES & 4.189 & 2.026 & .236 & -1.19 & 9.56 \\
\hline & & TIP REGULARLY & 3.954 & 1.648 & .102 & -.42 & 8.33 \\
\hline \multirow{12}{*}{ 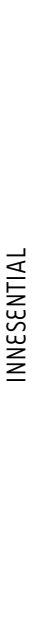 } & \multirow{3}{*}{ DO NOT TIP } & TIP SOMETIMES & .32780423 & .23819236 & 1.000 & -.3040335 & .9596420 \\
\hline & & TIP REGULARLY & $.59628991^{\star}$ & .22363224 & .048 & .0030748 & 1.1895050 \\
\hline & & TIP ALWAYS & $.67575405^{\star}$ & .22180225 & .015 & .0873933 & 1.2641148 \\
\hline & \multirow{3}{*}{$\begin{array}{c}\text { TIP } \\
\text { SOMETIMES }\end{array}$} & DO NOT TIP & -.32780423 & .23819236 & 1.000 & -.9596420 & .3040335 \\
\hline & & TIP REGULARLY & .26848568 & .14495925 & .389 & -.1160385 & .6530099 \\
\hline & & TIP ALWAYS & .34794982 & .14211982 & .089 & -.0290424 & .7249420 \\
\hline & \multirow{3}{*}{$\begin{array}{c}\text { TIP } \\
\text { REGULARLY }\end{array}$} & DO NOT TIP & $-.59628991^{*}$ & .22363224 & .048 & -1.1895050 & -.0030748 \\
\hline & & TIP SOMETIMES & -.26848568 & .14495925 & .389 & -.6530099 & .1160385 \\
\hline & & TIP ALWAYS & .07946414 & .11607680 & 1.000 & -.2284454 & .3873737 \\
\hline & \multirow{3}{*}{ TIP ALWAYS } & DO NOT TIP & $-.67575405^{\star}$ & .22180225 & .015 & -1.2641148 & -.0873933 \\
\hline & & TIP SOMETIMES & -.34794982 & .14211982 & .089 & -.7249420 & .0290424 \\
\hline & & TIP REGULARLY & -.07946414 & .11607680 & 1.000 & -.3873737 & .2284454 \\
\hline
\end{tabular}

Source: Author's calculations

*The mean difference is significant at .05 level

As expected, those who do not tip indicate strongly that they find it inessential to tip and that their view contrasts to that of the regular and always tippers. In addition, the always-tippers also disagree not only with the non-tippers, but also with the sometimes-tippers on the inessentiality of tipping (see TABLE 3). 
TABLE 4: Bonferroni corrections (continued)

\begin{tabular}{|c|c|c|c|c|c|c|c|}
\hline & \multicolumn{2}{|c|}{$\begin{array}{c}\text { BONFERRONI - } \\
\text { DEPENDENT VARIABLE }\end{array}$} & $\begin{array}{c}\text { Mean } \\
\text { Difference } \\
(1-J)\end{array}$ & Std. Error & Sig. & $\begin{array}{l}\text { Lower } \\
\text { Bound }\end{array}$ & $\begin{array}{l}\text { Upper } \\
\text { Bound }\end{array}$ \\
\hline \multirow{12}{*}{ 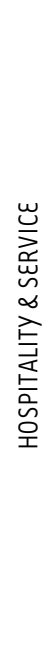 } & & TIP SOMETIMES & -.10708820 & .24389876 & 1.000 & -.7540630 & .5398866 \\
\hline & DO NOT TIP & TIP REGULARLY & -.15016015 & .22898983 & 1.000 & -.7575869 & .4572667 \\
\hline & & TIP ALWAYS & -.42808952 & .22711599 & .361 & -1.0305457 & .1743667 \\
\hline & & DO NOT TIP & .10708820 & .24389876 & 1.000 & -.5398866 & .7540630 \\
\hline & $\begin{array}{c}\text { TIP } \\
\text { SOMETIMES }\end{array}$ & TIP REGULARLY & -.04307194 & .14843206 & 1.000 & -.4368083 & .3506644 \\
\hline & & TIP ALWAYS & -.32100132 & .14552460 & .168 & -.7070252 & .0650226 \\
\hline & & DO NOT TIP & .15016015 & .22898983 & 1.000 & -.4572667 & .7575869 \\
\hline & $\begin{array}{c}\text { IIP } \\
\text { REGUIARIY }\end{array}$ & TIP SOMETIMES & .04307194 & .14843206 & 1.000 & -.3506644 & .4368083 \\
\hline & & TIP ALWAYS & -.27792937 & .11885767 & .119 & -.5932156 & .0373568 \\
\hline & & DO NOT TIP & .42808952 & .22711599 & .361 & -.1743667 & 1.0305457 \\
\hline & TIP ALWAYS & TIP SOMETIMES & .32100132 & .14552460 & .168 & -.0650226 & .7070252 \\
\hline & & TIP REGULARLY & .27792937 & .11885767 & .119 & -.0373568 & .5932156 \\
\hline \multirow{12}{*}{ 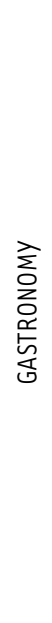 } & & TIP SOMETIMES & .14264313 & .24309305 & 1.000 & -.5021944 & .7874806 \\
\hline & DO NOT TIP & TIP REGULARLY & -.21205649 & .22823337 & 1.000 & -.8174767 & .3933637 \\
\hline & & TIP ALWAYS & -.29278828 & .22636572 & 1.000 & -.8932543 & .3076777 \\
\hline & & DO NOT TIP & -.14264313 & .24309305 & 1.000 & -.7874806 & .5021944 \\
\hline & $\begin{array}{c}\text { TIP } \\
\text { SOMETIMES }\end{array}$ & TIP REGULARLY & -.35469962 & .14794172 & .102 & -.7471352 & .0377360 \\
\hline & & TIP ALWAYS & $-.43543141^{*}$ & .14504386 & .017 & -.8201801 & -.0506828 \\
\hline & & DO NOT TIP & .21205649 & .22823337 & 1.000 & -.3933637 & .8174767 \\
\hline & REGULARIY & TIP SOMETIMES & .35469962 & .14794172 & .102 & -.0377360 & .7471352 \\
\hline & & TIP ALWAYS & -.08073180 & .11846502 & 1.000 & -.3949764 & .2335129 \\
\hline & & TIP SOMETIMES & .29278828 & .22636572 & 1.000 & -.3076777 & .8932543 \\
\hline & TIP ALWAYS & TIP REGULARLY & $.43543141^{*}$ & .14504386 & .017 & .0506828 & .8201801 \\
\hline & & TIP ALWAYS & .08073180 & .11846502 & 1.000 & -.2335129 & .3949764 \\
\hline
\end{tabular}

Source: Author's calculations

*The mean difference is significant at .05 level

Two reasons for dining out were identified by the ANOVA as determinants of tipping behaviour: gastronomy as well as hospitality and service. The Bonferroni test results indicated that in terms of hospitality and service there are merely moderately significant differences between those who tip regularly and those who always tip, with the always-tippers valuing hospitality and service more highly than the regular-tippers. In terms of gastronomy, the significant differences occur between those who tip sometimes and those who tip regularly and always. For the more consistent tippers (i.e. regular and always tippers) gastronomy is more important than for those who tip 
sometimes, indicating that the quality of the food is more important for the more consistent tippers (see TABLE 4).

TABLE 5: Bonferroni corrections (continued)

\begin{tabular}{|c|c|c|c|c|c|c|c|}
\hline & & & Mean & & & $95 \%$ Confic & ce Interval \\
\hline & $R R O N I-D E P E I$ & DENT VARIABLE & Difference & Std. Error & Sig. & Lower & Upper \\
\hline & & TIP SOMETIMES & .43432710 & .24322146 & .450 & -.2108510 & 1.0795052 \\
\hline & DO NOT TIP & TIP REGULARLY & .00907087 & .22835392 & 1.000 & -.5966691 & .6148108 \\
\hline & & TIP ALWAYS & .09268527 & .22648529 & 1.000 & -.5080979 & .6934684 \\
\hline & & DO NOT TIP & -.43432710 & .24322146 & .450 & -1.0795052 & .2108510 \\
\hline$\Xi$ & $\begin{array}{c}\text { TIP } \\
\text { SOMETIMES }\end{array}$ & TIP REGULARLY & $-.42525622^{*}$ & .14801986 & .026 & -.8178991 & -.0326133 \\
\hline$\stackrel{\infty}{\llcorner}$ & & TIP ALWAYS & -.34164183 & .14512048 & .115 & -.7265937 & .0433101 \\
\hline$\sum_{\Sigma}^{\omega}$ & & DO NOT TIP & -.00907087 & .22835392 & 1.000 & -.6148108 & .5966691 \\
\hline 齐 & $\begin{array}{c}\text { TIP } \\
\text { REGIULIY }\end{array}$ & TIP SOMETIMES & $.42525622^{*}$ & .14801986 & .026 & .0326133 & .8178991 \\
\hline & & TIP ALWAYS & .08361439 & .11852760 & 1.000 & -.2307962 & .3980250 \\
\hline & & DO NOT TIP & -.09268527 & .22648529 & 1.000 & -.6934684 & .5080979 \\
\hline & TIP ALWAYS & TIP SOMETIMES & .34164183 & .14512048 & .115 & -.0433101 & .7265937 \\
\hline & & TIP REGULARLY & -.08361439 & .11852760 & 1.000 & -.3980250 & .2307962 \\
\hline & & TIP SOMETIMES & -.32021920 & .24038421 & 1.000 & -.9578712 & .3174328 \\
\hline & DO NOT TIP & TIP REGULARLY & -.45319601 & .22569012 & .272 & -1.0518699 & .1454778 \\
\hline & & TIP ALWAYS & $-.74506256^{*}$ & .22384328 & .006 & -1.3388374 & -.1512877 \\
\hline & & DO NOT TIP & .32021920 & .24038421 & 1.000 & -.3174328 & .9578712 \\
\hline & $\begin{array}{c}\text { TIP } \\
\text { SOMETIMES }\end{array}$ & TIP REGULARLY & -.13297681 & .14629317 & 1.000 & -.5210394 & .2550858 \\
\hline 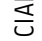 & & TIP ALWAYS & $-.42484336^{*}$ & .14342761 & .020 & -.8053047 & -.0443820 \\
\hline$\gtreqless$ & & DO NOT TIP & .45319601 & .22569012 & .272 & -.1454778 & 1.0518699 \\
\hline & $\begin{array}{c}\text { TIP } \\
\text { REfIIV }\end{array}$ & TIP SOMETIMES & .13297681 & .14629317 & 1.000 & -.2550858 & .5210394 \\
\hline & & TIP ALWAYS & -.29186655 & .11714494 & .079 & -.6026095 & .0188764 \\
\hline & & DO NOT TIP & $.74506256^{*}$ & .22384328 & .006 & .1512877 & 1.3388374 \\
\hline & TIP ALWAYS & TIP SOMETIMES & $.42484336^{*}$ & .14342761 & .020 & .0443820 & .8053047 \\
\hline & & TIP REGULARLY & .29186655 & .11714494 & .079 & -.0188764 & .6026095 \\
\hline & & TIP SOMETIMES & -651.102 & 892.435 & 1.000 & -3018.41 & 1716.20 \\
\hline$\stackrel{5}{z}$ & DO NOT TIP & TIP REGULARLY & -705.045 & 837.882 & 1.000 & -2927.64 & 1517.55 \\
\hline$\sum_{w}$ & & TIP ALWAYS & $-2208.589^{\star}$ & 831.026 & .049 & -4413.00 & -4.18 \\
\hline$\tilde{c}$ & & DO NOT TIP & 651.102 & 892.435 & 1.000 & -1716.20 & 3018.41 \\
\hline Ł & $\begin{array}{c}\text { TIP } \\
\text { SOMETIMES }\end{array}$ & TIP REGULARLY & -53.944 & 543.119 & 1.000 & -1494.64 & 1386.75 \\
\hline & & TIP ALWAYS & $-1557.487^{\star}$ & 532.480 & .022 & -2969.96 & -145.01 \\
\hline
\end{tabular}




\begin{tabular}{clcccccc}
\hline & & Mean & & \multicolumn{3}{c}{ 95\% Confidence Interval } \\
BONFERRONI - DEPENDENT VARIABLE & $\begin{array}{c}\text { Difference } \\
(I-J)\end{array}$ & Std. Error & Sig. & $\begin{array}{c}\text { Lower } \\
\text { Bound }\end{array}$ & $\begin{array}{c}\text { Upper } \\
\text { Bound }\end{array}$ \\
\hline \multirow{2}{*}{ TIP } & DO NOT TIP & 705.045 & 837.882 & 1.000 & -1517.55 & 2927.64 \\
REGULARLY & TIP SOMETIMES & 53.944 & 543.119 & 1.000 & -1386.75 & 1494.64 \\
& TIP ALWAYS & $-1503.543^{*}$ & 434.905 & .004 & -2657.19 & -349.90 \\
& DO NOT TIP & $2208.589^{*}$ & 831.026 & .049 & 4.18 & 4413.00 \\
TIP ALWAYS & TIP SOMETIMES & $1557.487^{*}$ & 532.480 & .022 & 145.01 & 2969.96 \\
& TIP REGULARLY & $1503.543^{*}$ & 434.905 & .004 & 349.90 & 2657.19 \\
\hline
\end{tabular}

\section{Source: Author's calculations}

*The mean difference is significant at .05 level

Regarding the size of the tip, the payment and bil/factor is more important to the regular-tippers than to the sometimes-tippers. Hence, a larger bill will result in a larger tip while in addition, the method of payment also leads to a larger tip; for example, if visitors can pay by credit card. Concerning the reasons for tipping, financia/ was the only significant variable identified by the ANOVA, indicating that the always-tippers and regular tippers feel that it is more important than the other tipping categories, which implies that they are of the view that they are making a financial contribution to the waiter's income, taking into consideration that most waiters in South Africa are temporary workers. With regard to total spending, the always-tippers are the most affluent patrons while dining out, and will also tip generously, compared to the other categories, least of all to the regular-tippers, who also evidenced an inclination to higher total spending (see TABLE 5).

\section{FINDINGS AND IMPLICATIONS}

The following findings were based on the analysis results: Firstly, whilst most studies dealing with tipping behaviour did not include the reasons why people dine out, this study sought to establish whether the reasons for dining out had an influence on tipping. Results indicated that gastronomy, one of the three reasons why people dine out and identified as a determinant of tipping in general, also played an important role in the Bonferroni correction results (TABLE 2). Therefore, future research should include the reasons for dining out, as the current research did conclude that tipping behaviour is influenced by the quality of food and the dining experience offered by the restaurant.

Secondly, the factors that influence the size of the tip (tipping behaviour) corroborate research conducted previously. Four factors influence the size of the tip: notably the restaurant's attributes, including factors such as its location, the type of restaurant and so forth, thereby confirming research conducted by Rind and Strohmetz (2001) and Lynn and Thomas-Haysbert (2003). Issues of hospitality and service have been identified and confirmed by Bodvarsson and Gibson (1997), Azar (2003), Lynn and McCall (2000) and Saayman and Saayman (2015). With regard to findings of payment and bill, these also confirmed research results from work undertaken by Lynn and McCall (2000) and Lynn (2006). Finally, results of the study confirmed issues of standardization in work done by Namasivayam and Upenja (2007), although this factor was not statistically significant. 
Thirdly, it was found that there are more behavioural variables influencing tipping and the typology than socio-demographic variables, which contradicts research conducted by ThomasHaysbert (2002). In fact, the results are so biased towards behavioural variables that it is not possible to draw a profile of the type of tipper other than the fact that they are high earners and they spend the most. Once again these results confirm the importance of including behavioural variables in this type of research.

Fourthly, the research confirms that approximately $6 \%$ of patrons do not tip, which is a percentage slightly higher than studies by Bodvarsson and Gibson (1997) and Thomas-Haysbert (2002) suggest. However, most of the respondents are regular tippers. This research also confirms that the key reasons for tipping are financial, which supports research by Lynn and Grassman (1990), Speer (1997), Saayman (2014), Whaley et al (2014), Saayman and Saayman (2015), followed by quality service which confirms research by Lynn and McCall (2000), Azar (2005). Finally since it is socially acceptable the results reinforce research by Azar $(2004 ; 2005 ; 2006 ; 2007)$. Concerning the reasons why patrons do not tip, two reasons were identified, namely bad service and tipping is inessential. Most research did not focus on this aspect, to the authors' best knowledge. Therefore, it is difficult to undertake comparisons.

Fifthly, results from the ANOVA indicate that where the determinants of tipping include age where older patrons tip more and total spendingincludes the finding of: the bigger the bill the higher the tip, gastronomy includes quality of food, quality service by waiters, size of bill and method of payment, making a financial contribution to the waiter's income while in the case where patrons do not tip, it was felt it is inessential. From these determinants it is important to note that gastronomy, which influences the size of the tip, has to do with the quality of food and the food experience. Therefore, this particular aspect is not in the hands of the waiter, but does influence their tip as well as the spending of patrons in general (TABLE 3). Waiters evidently have control over some aspects (for example, the service and hospitality they provide), whilst they do not have any control other aspects; for example the quality of the food. Concerning the tipping policy for restaurants, these results rather tend to support a free market approach than an all-inclusive bill. The latter might lead to a decline in income as most patrons are regular tippers and there are just $6 \%$ who do not tip. Moreover, the restaurant and waiter will benefit from training and improving service delivery.

Lastly, in relation to the purpose of this article, this research confirms that there are different markets or a typology of tippers; in this case there were four: those that do not tip, those that sometimes tip, those that regularly tip and those that always tip. These markets or types differ in their tipping behaviour. For example, those that always tip, value hospitality and service higher than other types, while gastronomy is more important to the regular tippers compared to those who do not tip or only tip sometimes. It is furthermore clear that for the regular tippers the method of payment and the size of the billis more important, as they are the more affluent patrons.

\section{CONCLUSION}

The purpose of this article was to distinguish different markets or types of tippers; the question of whether one can distinguish between different types arose. The results clearly indicated that there are different types and that one can distinguish between them. The big tippers are older, earn more and value the quality of food at the restaurant more highly as do they the level of service by waiters, compared to those that tip less. Therefore, for the big tipper, the type of restaurant is also important as are aspects such as location, menu and so forth. This is the first 
time, to the authors' knowledge, that an analysis of this kind has been performed in South Africa and may be regarded as novel research since it introduces aspects not used in the same analysis previously, such as reasons why people dine out and why people do tip. The article also makes a contribution in terms of identifying the determinants of tipping in general, indicating that most of those determinants are behavioural. It furthermore sheds light on the tipping behaviour in a developing country. This study could be expanded to include different cultures in order to obtain a greater understanding of different cultures' tipping behaviour.

\section{LIST OF REFERENCES}

Azar, 0.H. (2003). The implications of tipping for economics and management. International Journal of Socia/Economics, 30(10), pp. 1084-1094.

Azar, 0.H. (2004). Optimal monitoring with external incentives: the case of tipping. Southern Economic Journal, 71 (1), pp. 170-181.

Azar, 0.H. (2005). The social norm of tipping: does it improve social welfare? Journal of Economics, 85 (2), pp. 141-173.

Azar, 0.H. (2006). Tipping, firm strategy, and industria/ organization. Available: http://mpra.ub.unimuenchen.de/4485/1/MPRA_paper_4485.pdf (Accessed 14 November 2014).

Azar, 0.H. (2007). The social norm of tipping: a review. Journal of Applied Social Psychology, 37(2), pp. 380-402.

Azar, 0.H. (2011). Business strategy and the social norm of tipping. Journal of Economic Psychology, 32(3), pp. 515-525.

Barkan, R., Erev, I., Zinger, E. \& Tzach, M. (2004). Tip policy, visibility and quality of service in cafés. Tourism Economics, 10(4), pp. 449-462.

Bible. (2011). Holy Bible, New International Version. USA: Colorado Springs, Biblica Publishers.

Bodvarsson, O.B. \& Gibson, W.A. (1994). Gratuities and customer appraisal of service: Evidence from Minnesota restaurants. The Journal of Socio-Economics, 23(3), pp. 287-302.

Bodvarsson, O.B. \& Gibson, W.A. (1997). Economics and restaurant gratuities: determining tip rates. American Journal of Economics and Sociology, 56(2), pp. 187-203.

Bujisic, M., Choi, Y., Parsa, H.G. \& Krawczyk, M. (2013). Tipping practices in food and beverage operations: a longitudinal study. Journal of Culinary Science \& Technology, 11(3), pp. 241-258.

Crespi, L. P. (1947). The implications of tipping in America. Public Opinion Quarterly, 11(3), pp. 424435.

Field, A. (2009). Discovering statistics using SPSS. London, UK: Sage Publications.

Greenberg, A.E. (2014). On the complementarity of prosocial norms: The case of restaurant tipping during the holidays. Journal of Economic Behaviour and Organization, 97(1), pp. 103-112.

Lynn, M. \& Grassman, A. (1990). Restaurant tipping: an examination of three 'rational'explanations. Journal of Economic Psychology, 11(2), pp. 169-181.

Lynn, M. \& Sturman, M. C. (2003). It's simpler than it seems: an alternative explanation for the magnitude effect in tipping. International Journal of Hospitality Management, 22(1), pp. 103-110. 
Lynn, M. \& Thomas-Haysbert, C. (2003). Ethnic differences in tipping: Evidence, explanations, and implications. Available:

http://scholarship.sha.cornell.edu/cgi/viewcontent.cgi?article=1107\&context=articles (Accessed 14 November 2014).

Lynn, M. \& McCall, M. (2000). Gratitude and gratuity: a meta-analysis of research on the servicetipping relationship. The Journal of Socio-Economics, 29(1), pp. 203-214.

Lynn, M. \& Withiam, G. (2008). Tipping and its alternatives: business considerations and directions for research. Journal of Services Marketing, 22(4), pp. 328-336.

Lynn, M (2006). Tipping in restaurants and around the globe: An interdisciplinary review. In Altman, M. (ed.) Handbook of contemporary behavioral economics: Foundations and development. New York: Sharpe Publishers (pp. 626-643).

Miller, B. (2010). Compensation practices in restaurants and the impact on service quality. Journal of Foodservice Business Research, 13(1), pp. 24-35.

Mkono, M. (2011). Tipping practices and policies in Zimbabwe's hotel industry: Impacts on restaurant waiters' service delivery and work relationships. Journal of Foodservice Business Research, 14(4), pp. $414-425$.

Namasivayam, K. \& Upenja, A. (2007). Employee preferences for tipping systems. Journa/ of Foodservice Business Research, 10(2), pp. 93-107.

Paul, P. \& Gardyn, R. (2001). The tricky topic of tipping. American Demographics, 23(5), pp. 10-11.

Rind, B. \& Strohmetz, D. (2001). Effect of beliefs about future weather conditions on restaurant tipping. Journal of Applied Social Psychology, 31(10), pp. 2160-2164.

Saayman, M. (2014). To tip or not to tip. African Journal of Hospitality Tourism Leisure, 3(2), pp. 115.

Saayman, M. \& Saayman, A. (2006). Does the location of arts festivals matter for the economic impact?. Papers in Regional Science, 85(4), pp. 569-584.

Saayman, M. \& Saayman, A. (2015). Understanding tipping behaviour: An economic perspective. Tourism Economics, 21(2), pp. 247-265

Seiter, J.S. \& Weger, H. (2013). Does a customer by any other name tip the same? The effect of forms of address and customers' age on gratuities given to food servers in the United States. Journal of Applied Social Psychology, 43(8), pp. 1592-1598.

Speer, T.L. (1997). The give and take of tipping. American Demographics, 19, pp. 50-54.

Thomas-Haysbert, C.D. (2002). The effect of race, education and income on tip ping behaviour. Journal of Foodservice Business Research, 5(2), pp. 47-60.

Van Wyk, L., Saayman, M. \& Rossouw, R. (2013). Economic impact of the Klein Karoo National Arts Festival: investigating the application of different models. Journal of Economic and Financial Sciences, 6(1), pp. 129-152.

Whaley, J.E., Douglas, A.C. \& O'Neil, M.A. (2014). What's in a tip? The creation and refreshment of a restaurant-tipping motivations scale: A consumer perspective. International Journal of Hospitality Management, 37(1), pp. 121-130. 